\title{
A escrita nas psicoses: suas funções e seus destinos em uma oficina literária*1
}

\section{The act of writing in psychoses: its functions and fates in a literary workshop}

\author{
Manoela Nunes de Freitas*2 \\ Angélica Bastos*3
}

\begin{abstract}
$O$ artigo aborda a experiência de acompanhar psicóticos em uma oficina literária de escrita e produção de jornal em um CAPS III. O objetivo consiste em recolher os efeitos do ato de escrever, sobretudo escrever junto com os outros. O procedimento apoia-se nas memórias de Schreber, na obra literária de James Joyce e no recurso a fragmentos do trabalho na oficina, com base em $S$. Freud e J. Lacan. Conclui-se que os efeitos da participação nas atividades coletivas compreendem o endereçamento a outrem $e$ a produção da letra destinada ao lixo, graças à qual se extrai o excesso de gozo.
\end{abstract}

Palavras-chave: Psicose, escrita, psicanálise, oficina literária

${ }^{* 1}$ Este artigo constitui um desdobramento de pesquisa relativa à dissertação de mestrado defendida por Manoela Nunes de Freitas no Programa de Pós-gradua- ção em Teoria Psicanalítica do Instituto de Psicologia da Universidade Federal do Rio de Janeiro - UFRJ (Rio de Janeiro, RJ, Brasil).

*2 CAPS III Franco Basaglia (Rio de Janeiro, RJ, Brasil).

${ }^{* 3}$ Universidade Federal do Rio de Janeiro - UFRJ (Rio de Janeiro, RJ, Brasil). 


\section{Como acompanhar o trabalho espontâneo nas psicoses?}

Na clínica com as psicoses, testemunhamos inúmeras soluções inventadas pelos sujeitos para lidar com um mal-estar que se apresenta muitas vezes de forma radical e deslocalizada, gerando isolamento e precariedade nos laços. Trata-se de soluções singulares que passam ao largo dos padrões do senso comum. Ao analisar o caso do presidente Daniel Paul Schreber, Freud (1911/2006d) percebeu nesses casos uma defesa que implica um desligamento do investimento libidinal depositado nos objetos, tais como pessoas e coisas. Esse desligamento envolve um retorno do investimento ao eu, acarretando um excesso de libido insuportável característico, por exemplo, das vivências de fragmentação corporal na esquizofrenia e de megalomania na paranoia.

Esse estado requer o tratamento e a redistribuição da libido a partir da invenção de um modo de reinvesti-la novamente e dar-lhe um novo destino. Tal é o trabalho próprio do psicótico no sentido de um restabelecimento, de uma reconstrução: uma tentativa espontânea de cura. Diante da ruptura entre o sujeito e o mundo, entendida como perda da realidade, o delírio serve como um "remendo" para essa fenda que se abriu entre ele e o mundo externo (Ibid.).

Apesar da apresentação frequentemente ruidosa e disruptiva dos sintomas psicóticos, estes se interpõem como um trabalho e uma resposta do sujeito ao seu sofrimento, tal como indicado por Freud (Ibid.) a propósito do estatuto do delírio. A vivência do excesso, o qual se apresenta na relação com a linguagem, com o corpo e com os outros, muitas vezes requer a presença de um clínico que acompanhe as estratégias singulares de defesa ao que é invasivo e auxilie na construção dos recursos para localizar o gozo desregulado. 
Neste sentido, os serviços de saúde mental, especialmente os Centros de Atenção Psicossocial ${ }^{1}$ (CAPS), vão na contramão da institucionalização da loucura, na medida em que se propõem a acompanhar no um a um os modos de recuperação e as maneiras como cada um trata o que atordoa. Com o objetivo de construir um projeto terapêutico singular (PTS) para cada caso, esses serviços se organizam de forma a acolher a multiplicidade de respostas que cada sujeito inventa para lidar com seu mal-estar, dando lugar e aprendendo com elas, em vez de impor, mediante um protocolo, um tratamento universal estipulado previamente. As diversas modalidades de oficinas terapêuticas disponíveis nesses serviços possibilitam ao psicótico encontrar acolhida para o trabalho espontâneo feito por ele, muitas vezes iniciado antes mesmo de chegar ao tratamento. Elas ainda visam propiciar o início desse trabalho psíquico, quando o sujeito chega em pleno surto ou diante de uma grande ruptura com a vida.

Encontramos em Zenoni (2000) direções para este trabalho clínico com a psicose a partir da indicação de uma posição de aprendizagem em relação à clínica. Por esta via, o clínico se permite aprender sobre as soluções que cada caso encontra para lidar com a falta central no simbólico e se deixa aprender como praticar. Trata-se de uma posição de "sujeito suposto não saber" (p. 20) que deixa ao sujeito a iniciativa de saber e não alimenta uma posição intrusiva ou persecutória de transferência.

Deste modo, a posição de "aprendiz da clínica" (Zenoni, 2000), permite ao técnico do serviço, em vez de encarnar aquele que sabe sobre o sujeito, ocupar um lugar esvaziado de saber, além de permiti-lo secretariar a produção psicótica. Também é facultado ao clínico ocupar um lugar de endereçamento desta produção, fazendo-se seu destinatário, ajudando a localizá-la e a dar-lhe um destino, conforme veremos a seguir.

Passamos ao relato da experiência de uma coordenadora de uma oficina literária de escrita e produção de jornal em um CAPS III. ${ }^{2}$ A partir da posição de aprendiz da clínica, pôde-se construir um trabalho à proporção que, na oficina, reúnem-se semanalmente alguns usuários, na maioria psicóticos, que

${ }^{1}$ Serviço de saúde mental aberto e comunitário do Sistema Único de Saúde (SUS) criado para ser substitutivo ao hospital psiquiátrico, atendendo pessoas em grave sofrimento psíquico (Brasil, 2004).

${ }^{2}$ Modalidades de Centros de Atenção Psicossocial que funcionam 24h por dia com leitos para acolhimento noturno às situações de crise. 


\section{SAÚDE MENTAL}

possuem uma relação muito especial com a escrita e com a leitura e para os quais o ato de escrever se impôs em suas vidas. No encontro semanal com pessoas que se utilizam do escrever, que muitas vezes já ocorre de forma solitária para alguns, esta atividade pôde se tornar coletiva e ter um lugar na instituição de saúde mental, integrando-se ao tratamento.

A escrita pode se colocar como um recurso para qualquer sujeito, neurótico ou psicótico, delirante ou não. Interessa-nos, no entanto, examinar a função assumida pelo ato de escrever nos casos de psicose e verificar se, em alguns deles, a escrita serviu de solução para lidar com o excesso que acomete o sujeito. A pertinência dessas questões se ratifica diante de um fato que salta aos olhos: muito se escreve nesses casos, como acontece com Schreber, James Joyce. Basta uma breve passagem por um CAPS, ou simplesmente pelas instituições de saúde mental, e logo se nota algum usuário com muitos cadernos, outro escrevendo em uma folha ou alguém para quem é de muita importância, por exemplo, o registro escrito de marcação de consultas no cartão de retorno.

Percebe-se logo que muitos se servem da escrita, mas, conforme é indicado por Holck (2010), não é possível prescrever a escrita ou prever seus efeitos para alguém. Somente é possível verificar sua função para cada um, na medida em que, para alguns, é preciso escrever e estes se deixam levar pela escrita. Assim, diante das inúmeras soluções inventadas nas psicoses para lidar com o que é disruptivo e atordoante, vemos que a escrita se impõe como um recurso cuja função é preciso explorar.

A convivência semanal com psicóticos que escrevem suscitou muitas questões: Que trabalho é esse feito pela escrita? Sobre o que se trabalha? O que se constrói com o texto? Qual a relação da escrita com o corpo? e, além disso, qual o lugar do clínico diante dos escritos dos psicóticos? Deste modo, ao interrogarmos o papel da escrita, buscamos recolher as transformações que $o$ ato de escrever, sobretudo escrever com os outros, produz na relação do sujeito com a linguagem, com o corpo próprio e com seu mundo.

\section{Sobre a escrita e os destinos do gozo}

Freud (1894/2006b) constata desde o início de sua obra que o mal-estar está colocado para todo ser falante e que, em cada estrutura, há maneiras diferentes de lidar com o que é insuportável. Lacan (1972-73/2008) indica que esse mal-estar é inaugurado pelo encontro do vivente com as palavras, assim que ele vem ao mundo, palavras vindas da língua materna, o que ele chama de 
lalíngua. Esta não envolve endereçamento, não serve ao diálogo, mas deixa marcas no corpo do infans. $\mathrm{O}$ excesso de afeto provindo deste encontro requer modos de defesa e de tratamento. Tais defesas podem tramitar por uma via na qual os significantes desarticulados vindos do Outro adquirem um sentido delirante mediante a construção de um saber. Na neurose, o tratamento que se dá a esse enxame de significantes no qual o vivente está imerso corresponde ao trabalho de escritura do inconsciente, que extrai de lalíngua o que é do significante, introduzindo uma diferença para outro significante. Esta é uma maneira de localizar o gozo, inserindo-o no discurso, o que possibilita o laço social na neurose. Trata-se da simbolização que constitui um modo específico de se estar no mundo.

Mandil (2003) indica que cada língua não passa de um modo de defesa, de apaziguamento e de adormecimento do que há de enlouquecedor e de impositivo em nossa relação com as palavras. Assim, com o modo de constituição do sujeito na neurose, Lacan (1972-73/2008) nos diz que a linguagem se torna um modo de tratar o gozo instaurado nesse encontro com lalíngua, implicando um modo específico de escrita do inconsciente - a do inconsciente estruturado como uma linguagem $\left(\mathrm{S}_{1}-\mathrm{S}_{2}\right)$ - que possibilita 76 ao neurótico ficar um pouco surdo aos ruídos da língua e ao fato de que ela nos é imposta. Deste modo, "a linguagem, sem dúvida, é feita de lalíngua. É uma elocubração de saber sobre lalíngua. Mas o inconsciente é um saber, um saber-fazer com lalíngua (p. 149).

Neste sentido, Bastos e Freire (2006) pontuam que o ser humano está desde sempre no verbo, mas que é graças a um trabalho do infans que este pode passar da condição de falado à condição de falante. Esse é um trabalho de subjetivar a fala que precede a criança, na qual se nasce aprisionado como objeto, tomado por um gozo não localizado. É no só-depois que o inconsciente é articulado como linguagem $\left(\mathrm{S}_{1}-\mathrm{S}_{2}\right.$, ) a partir de lalíngua.

Na neurose, com o recurso ao Nome-do-Pai, há uma experiência de organização do que Freud (1905/2006c) chamou de pulsões autoeróticas, o que proporciona uma experiência de unificação corporal. Isso acontece porque há uma perda de gozo com sua localização nas zonas erógenas do corpo, na medida em que se condensa o gozo a partir da extração do objeto $a$. Com a extração desse objeto, separando sujeito e Outro, perde-se uma "libra de carne" e desmarca-se o lugar de uma falta estrutural, um lugar vazio, localizando-se um lugar próprio ao aparecimento da angústia (Lacan, 1962-63/2005).

A partir dessa estrutura, é possível que parte do gozo aceda ao discurso, o que permite ao sujeito fazer laço. No entanto, o último ensino é todo 


\section{SAÚDE MENTAL}

fundado sobre a impossibilidade de a relação sexual entre os falantes existir, asseverando que o encontro entre eles se dá sempre por uma disjunção da relação (Lacan, 1972-73/2008).

Portanto, há algo que, mesmo na neurose, não se escreve jamais, que Lacan (1972-73/2008) atribui ao fato de não haver relação sexual, o que implica que algo do gozo insiste sempre sem se inscrever/escrever e requisita um outro trabalho, uma outra forma de escrita, nomeada como a escrita dos nós no Seminário 23 (Lacan, 1975-76/2007). Assim, na neurose, uma parte desse excesso inaugural consegue ser localizado, delimitado e inscrito no aparelho psíquico. Já nas psicoses, ele é deslocalizado (Maleval, 2002), exigindo um esforço único para localizá-lo através de uma outra escrita.

\section{Os destinos do gozo nas psicoses}

Que escritas são possíveis nas psicoses, já que não se trata da escrita do inconsciente estruturado como uma linguagem tal como ocorre na neurose? De que forma se chega a localizar o gozo que se instaura pelo encontro com lalíngua? $\mathrm{O}$ ato de escrever, então, poderia delimitar o gozo, tecer um corpo, construir uma relação mais apaziguada com o Outro, bem como a invenção de uma maneira de enlace social? Com essa problemática, não pretendemos sustentar que a escrita literária venha, no terreno das psicoses, substituir a escrita do inconsciente estruturado pela metáfora, posto que a atividade de escrever está presente em muitos não psicóticos e ausente em psicóticos estabilizados que, no entanto, não se dedicam à tarefa de escrever. Visamos, antes, interrogar a função da escrita literária, ou mesmo de qualquer atividade de escrever, para psicóticos que sofrem do retorno do que não acedeu à escrita simbólica do inconsciente.

No Seminário 3 (Lacan, 1955-56/2002), dedicado às psicoses, atribui-se a psicose à foraclusão de um significante primordial - o significante do Nome-do-Pai — na entrada do sujeito no mundo simbólico. Isto implica uma recusa e um retorno do foracluído desde fora, resultando numa relação de exterioridade com a linguagem: ela vem de fora, retorna no real.

$\mathrm{Na}$ psicose não há a extração do objeto $a$, ele é carregado no bolso (Lacan, 1962-63/2005; 1967). Segundo Maleval (2002), isso faz com que o psicótico permaneça identificado como objeto de gozo do Outro, daí as injúrias sofridas nas alucinações, por exemplo. Ou seja, o psicótico se mostra tomado pela carga de um excesso. $\mathrm{O}$ gozo, não condensado sob a forma do 
objeto $a$, retorna de fora, não havendo o aparecimento da angústia de forma enquadrada, tal como Lacan (1962-63/2005) indica ocorrer na neurose.

A foraclusão é entendida como correspondente à carência de um princípio regulador. Ela acarretaria, por um lado, uma perda do ordenamento da cadeia significante na fragmentação esquizofrênica e sua solidificação na paranoia, e, por outro lado, uma falta de aptidão do sujeito para localizar o gozo por meio do significante, o que implica uma dificuldade de apaziguamento (Maleval, 2002).

Trata-se de verificar quais são as soluções nas psicoses para localizar o gozo, produzir algum contorno corporal e alívio ao que é vivido como excesso. Seria o ato de escrever na psicose uma solução para a dispersão das pulsões e os significantes desarticulados de lalíngua?

A libido que retorna de forma excessiva assume diferentes formas de invasão e requisita trabalhos diversos. Na esquizofrenia, com o retorno ao autoerotismo (Freud, 1911/2006d), vemos os fenômenos de fragmentação corporal devidos à ausência da fabricação de uma unidade proporcionada pelo narcisismo. Um modo de localizar esse gozo disperso repousa no tratamento de um órgão ou de uma parte do corpo (Lacan, 1966/2003), como o 78 uso de anéis por um sujeito para ligar o corpo, por exemplo (Miller, 2003). Na paranoia, o retorno ao narcisismo (Freud, 1911/2006d), implica as relações de puro espelhamento tão hostis com o semelhante. E com a imagem toda tomada de gozo, o delírio seria uma forma de reinvestir essa libido, localizando o gozo no Outro (Lacan, 1966/2003).

\section{A escrita nas psicoses: o que Schreber e Joyce nos ensinam}

Na psicose, a relação com a linguagem é peculiar. Suspeitamos que a relação com a escrita também o seja. A relação com o conjunto do aparelho de linguagem é de exterioridade, o psicótico é habitado por ela (Lacan, 1955-56/2002). Na neurose, a invenção do inconsciente estruturado como uma linguagem - o que vimos ser da ordem de uma inscrição, ou de uma escrita - é um modo de tratar a imposição de lalíngua e seu gozo no vivente, ou seja, uma maneira de ficar um pouco surdo ou desavisado do ruído das palavras.

O que se impõe ao sujeito como fora de si, o que vem de fora, muitas vezes exige ser tratado com recursos concretos e a produção de um texto ou de uma obra pode ter essa função. Schreber (Freud, 1905/2006c) nos deu 


\section{SAÚDE MENTAL}

inúmeros exemplos da imposição da linguagem para ele, da língua fundamental, e dos recursos inventados para lidar com a "tagarelice desvairada das vozes" (p. 121), sendo a escrita, um deles.

Laurent (1995) indica que "o sujeito psicótico escreve como o sujeito neurótico fala" (p. 184) e exemplifica este fato evocando os psicóticos reivindicadores que se utilizam de dossiês, relatórios e queixas nas delegacias ou nos serviços de psiquiatria. O psicótico torna-se, assim, seu próprio secretário dispondo de um sistema de notas, sistema que é tão substancial à psicose quanto o teatro interno no sujeito histérico.

Lacan (1955-56/2002) aponta que a escrita pode servir ao sujeito delirante como um recurso para organizar o próprio delírio. Este é construído a partir de um trabalho de articulação dos fenômenos invasivos de que sofre o psicótico: por isso, o delírio é tão mais sofrido quanto menos organizado ele for. As produções delirantes se desenvolvem em produções literárias, no sentido de literárias indicar "simplesmente folhas de papel cobertas com escrita" (p. 95).

Delirante e escritor, no testemunho escrito que nos dá sob a forma de seu livro, Schreber fala da solução de sua problemática. O que inspirou a construção dessa obra foi a vivência de ser "tagarelado", manipulado de todas as formas, e seu livro foi o "resultado de uma longa construção que foi para ele a solução de sua aventura interior" (p. 97). O livro de Schreber era um testemunho aberto, um discurso publicado, que almejava chegar ao leitor. Ele escreveu sua obra enorme para que ninguém ignorasse o que sofreu diante do seu médico Fleschisg e de Deus, seus perseguidores. Relata as invasões sofridas, mas também a solução que encontrou.

Schreber era escritor, mas não poeta (Lacan, 1955-56/2002, p. 96), porque a poesia nos introduz num mundo que podemos tomar também como nosso, do qual podemos nos apropriar, pela qual o leitor se sente de alguma forma ligado. Nas memórias do presidente, trata-se de algo diferente disso, vemos um testemunho de alguém que se encontra no lugar de objeto do Outro. $\mathrm{Na}$ escrita da loucura, há o testemunho do louco sem que ele esteja incluído como sujeito, com uma tonalidade objetiva, onde predomina a metonímia (Mandil, 2010). Então, muitas vezes, o psicótico pode escrever para falar do lugar de objeto que radicalmente ele ocupa e do sofrimento que isso implica.

$\mathrm{O}$ escritor irlandês James Joyce também nos ensina muito sobre a escrita como uma ferramenta clínica importante. O Seminário 23. O sinthoma (Lacan, 1975-76/2007) dedica-se à analise da relação entre corpo e escrita em Joyce, investigando em particular o saber-fazer joyceano com o falatório de lalíngua e o modo como cifra o gozo. A relação de Joyce com o corpo próprio 
é muito suspeita a Lacan. Este dado tem suporte em uma confidência feita no livro Retrato de um artista quando jovem, na qual o personagem Stephen, o Joyce que Joyce imagina, leva uma surra de seus colegas. Ao se perguntar por que não guardou rancor depois desse evento, o personagem constata que seu corpo se esvaiu "como a fruta é destituída da casca macia e madura" (Joyce, 2014, p. 99).

Conclui-se (Lacan, 1975-76/2007) que, em Joyce, há uma relação com o corpo próprio como estrangeiro, sob a forma de um deixar cair, como alguma coisa que pode ser largada como uma casca. Seu corpo não se constituiu pela via da imagem narcísica, que comportaria a ideia de si como um corpo. Quanto à relação do escritor com a linguagem, ela era sentida como um parasita falador, pois o ruído e o barulho o invadiam de forma atordoante e as falas lhe eram impostas. A partir desses dados clínicos, supõe-se que, no que se refere à relação de Joyce com os registros real, imaginário e simbólico, o imaginário desliza, soltando-se dos demais. Há, portanto, um erro no enlaçamento entre eles, o que requer um artifício para corrigi-lo.

O nó borromeano demonstra como os três registros se enlaçam. Este nó tem a característica de ser constituído por três anéis de forma que, se um se soltar, os demais também se soltam, sendo preciso um quarto elo para atá-los. Este quarto elo, o Sinthoma, ao enodar os registros, fornece um lugar ao objeto $a$, localizando, assim, o gozo. No caso das neuroses, os registros se amarram borromeanamente com o Nome-do-Pai, o qual funciona como o quarto elo que amarra as outras rodelas (Ibid.). O Nome-do-Pai passa a ser considerado um dos sinthomas possíveis, ou seja, um dos modos de amarrar os registros e, a partir daí, pode-se pensar o que pode funcionar como Sinthoma para cada um.

Em Joyce, a escrita passa a ter uma função importantíssima em relação ao erro do nó, na medida em que este se enoda por seu artifício. Assim, a arte da escrita neste caso é alçada ao estatuto de sinthoma, pois a partir de sua arte o nó é restabelecido. Portanto, a escrita tece seu ego, enoda o imaginário que deslizou como uma casca, produzindo um modo de amarração do corpo (Ibid.). Essa escrita não passa pela transmissão de um sentido ou de uma mensagem, mas serve como um recurso para tratar o parasitismo da linguagem e tecer seu corpo, aparelhando o gozo. Laia (2001) pontua que a obra joyceana situa-se como uma tessitura na qual o escritor organiza sua própria composição. Um meio pelo qual Joyce se aperta, se concerne como um nó, como algo que amarra e enlaça, onde o irrepresentável vai ganhando uma certa inscrição. 


\section{SAÚDE MENTAL}

Trata-se de uma escrita que constrói um texto cada vez mais ilegível ao longo de sua obra. Lacan (1975-76/2007) diz que, se podemos lê-lo, é porque "sentimos presente o gozo daquele que escreveu isso" (p. 161); essa gozação é a única coisa que podemos pegar do seu texto. Segundo Laurent (1995), percebe-se como Joyce faz equivaler, a partir de seu trabalho de escrita, letter e litter, letra e lixo, tal como se espera no fim de uma análise. O jogo de palavras joyceano não produz alívio ao leitor nem lhe permite rir. No entanto, Joyce ria ao escrever Finnegans Wake, num modo de arte que "abole assim o prazer do texto, mas onde se aparelha o gozo do autor" (p. 136).

\section{O trabalho do analista}

Interrogamos o trabalho do analista ou clínico com os textos dos psicóticos, já que não é pela via da interpretação que devemos tratá-los. Os escritos dos psicóticos não estão ali para serem analisados, decifrados, são objetos inanalisáveis, o que situamos a partir da indicação de Lacan (1972-73/2008) de que um escrito, ele não é para ser lido.

Schreber nos ensina algumas coisas: quando ele fala de seu lugar de objeto do gozo do Outro com o seu testemunho, almeja que seu discurso chegue ao leitor e à comunidade científica, pois queria transmitir algo do que tinha a completa certeza de ter vivido. Isto fica claro em sua "carta aberta" no começo de seu livro. Ou seja, o saber estava do seu lado e a transferência não tinha como motor o sujeito suposto saber, tal como ocorre na neurose.

Nesse sentido, a escuta do testemunho de uma relação com a linguagem extremamente singular e original do psicótico e a acusação de seu valor, tornam-se ferramentas importantes nessa clínica, visto que não devemos, então, ouvir do lugar de quem sabe sobre o sujeito, para não ocupar um lugar de quem também goza dele. Aprendemos com Schreber a ouvir o delírio e acusar seu recebimento, a partir de um lugar que Lacan (1955-56/2002) chamou de secretário do alienado.

Schreber nos ensina mais ainda com a publicação do seu testemunho sobre a forma de um livro acabado como um objeto: ao ocuparmos um lugar de furo, esvaziado de saber, podemos constituir também um lugar de endereçamento, a partir do qual o psicótico pode se desfazer de um papel escrito, de um objeto. Com um texto escrito num papel e entregue, há a cessão de algo, uma perda de gozo, proporcionando algum alívio para o sujeito. Desse modo, podemos pensar esse trabalho com a escrita na psicose pelo que é chamado 
por Laurent (1995) de lógica de um esvaziamento. Então, ao escrever, algo pode ser feito com o gozo que não se condensou sob a forma do objeto $a$ extraído do corpo e pode-se dar um destino ao gozo que não se inscreveu no aparelho psíquico, o qual continua assolando tanto o corpo quanto os pensamentos. Para Laia (2001) o escrito pode dar corpo às palavras e, lançando-o para fora de si, veicula o gozo e uma satisfação localizável na própria trama da escritura.

Laurent (1995) indica que o trabalho pela via do secretariar não consiste simplesmente em tomar notas, mas introduzir o sujeito no texto do psicótico, podendo ordenar, inclusive, a produção psicótica no tempo. Isso é valorizar a literatura como uma estrutura de distribuição do gozo, de esvaziamento.

Com o "Seminário sobre a carta roubada" e o texto sobre André Gide, Lacan (1956/1998a;1958/1998b) enfatiza a letra, ou uma carta, em um nível distinto da função mensageira, de sentido, vale dizer, privilegia sua dimensão de materialidade, que cumpre uma função em relação ao gozo. Elas veiculam mais do que uma mensagem, elas são veículos de gozo. O lugar do psicanalista, então, deve ser um lugar de furo que possibilite que a carta/letra, como lixo, venha a se perder, que um objeto possa se perder, a partir da função 82 eminente do secretário que é a de expedir as cartas, o que remete a despachar as letras, livrar-se delas (Laurent, 1995).

O termo "publixo" de Lacan (1972-73/2008, p. 32) nos ajuda a conceber a relação da publicação de um escrito com a ação de se desfazer de restos. A escrita pode, então, constituir um modo de defesa contra o que é vivido pelo sujeito como invasivo: uma escrita que sirva de recurso para lidar com o excesso, drenando o ruído da fala, inventando um enlace social e uma relação mais apaziguada com o corpo, tal como Joyce atesta.

Muñoz et al. (2014) apontam a escrita na psicose como um saber-fazer com o que se desregula, na medida em que esse recurso é capaz de articular restos da língua que requisitam o corpo. O texto, assim, possibilita delimitar um espaço vazio, produzindo uma borda e um escoamento do que é vivido como excesso. Para Mandil (2010), a literatura pode acolher esses procedimentos e, valendo-se da escrita, o psicótico pode, além de se defender dos aspectos enlouquecedores de sua relação com as palavras, estabelecer um novo laço com o social, inclusive através de sua inscrição como escritor.

Concluímos que a escrita, deste modo, pode ser um modo de reinvestir a libido que se acumulou no eu, uma via de escoamento do gozo e um modo de construir um lugar no Outro que não seja radicalmente o de objeto. No trabalho com a psicose, portanto, na posição de aprendiz da clínica (Zenoni, 


\section{SAÚDE MENTAL}

2000) e não na de quem sabe, o clínico pode ocupar esse lugar esvaziado de saber, além de secretariar a produção psicótica. Coloca-se também no lugar de destinatário dessa produção, aliando-se ao sujeito na invenção de um destino que se preste a localizá-la.

\section{Enlaces pela escrita}

Alguns usuários em um serviço de saúde mental — um hospital-dia que se transformou depois em um CAPS III - convidaram a analista recém-inserida na instituição para retomar com eles uma oficina que fora interrompida há alguns anos: uma oficina de confecção de um jornal. Uma vez aceito o convite, com lápis e papel, iniciaram-se encontros semanais para escreverem juntos. Passando a coordenar a oficina, a analista não sabia como ela seria e nem o que sairia dali; foi apenas acompanhando o que eles lhe indicavam e seguindo com eles.

O nome "Jornal" remetia equivocadamente a algo próximo de um noticiário, mas aos poucos ficou claro para a coordenadora da oficina que textos desse molde eram os mais raros. Apresentava-se uma tendência mais literária, que fica notória pelo próprio nome que os usuários propuseram para o jornal: $O$ bom navegante. Esse nome foi escolhido porque o serviço se chamava Cais — que não remete a uma sigla, mas simplesmente a cais do porto um nome mais poético para textos que seguiam suas rotas singulares, rotas traçadas por cada usuário para seus próprios escritos. O interessante é que tinham um ponto de ancoragem: o encontro semanal.

Assim, a oficina começou com a escrita livre e a publicação de textos no jornal, lançado a cada três meses. Um usuário, que há muitos anos tinha feito um curso de datilografia, se voluntariou desde o início a digitar os textos e, desde então, trata com afinco esse trabalho. Dessa forma, reúnem-se os usuários e a coordenadora, começam a escrever e, à medida que acabam, leem para o grupo em voz alta o que escreveram. Geralmente, tecem comentários sobre os textos, discutem o que ouviram ou falam de coisas da vida enquanto escrevem.

A oficina de escrita e publicação do jornal foi sofrendo modificações importantes e o número de escritores aumentou. No começo, quase todos os textos escritos eram publicados, parecia que eles escreviam sempre para a edição seguinte. Apesar das mudanças e reconfigurações da oficina até o presente momento, criou-se um espaço, sempre no mesmo dia e no mesmo 
horário, possibilitando cada vez mais algum laço entre pacientes, na sua maioria psicóticos, que já tinham alguma relação com a escrita e com a leitura. Ali podiam tornar coletivo um trabalho que já faziam de forma solitária.

$\mathrm{Na}$ maioria dos textos, trata-se de um trabalho feito por eles com a escrita e com a leitura nas suas dimensões mais distantes das tramas do sentido, os escritos são tratados, sobretudo, em sua dimensão de indizível, como um escrito que não é para ser lido (Lacan, 1972-73/2008, p. 32). Como indicou Laurent (1995), no texto do psicótico se valoriza a literatura não como ficção, não como uma exibição de identificações, mas como uma estrutura de distribuição do gozo, valorizando o texto como um modo de esvaziamento do que é vivido como excesso. Segundo Greco (2003), trata-se de um trabalho que produz significantes a partir do gozo, em um efeito de resposta ao que retorna no real e não um efeito de significação. São escritas que privilegiam mais o caráter material da letra do que sua vertente de mensagem.

Augusto escreve toda semana sobre um time de futebol. Ele nunca escreveu sobre outro assunto, tanto que quando vai começar sua leitura, os participantes sinalizam que já sabem sobre o que ele irá falar. Uma vez, quando contou de uma partida em que o time havia perdido, um participante da oficina lhe perguntou se ele tinha ficado triste com o resultado do jogo, ao que ele respondeu, surpreendendo, que não gostava muito desse time. Ficou claro que não é algo com o qual ele se identifica ou com que tenha alguma relação particular; simplesmente, é um assunto sobre o qual escreve.

Com o aumento expressivo dos participantes da oficina e com uma escrita mais regular e intensa, ficou inviável publicar tantos textos. Algumas questões que já se colocavam, ficaram ainda mais urgentes: todos os escritos teriam o mesmo destino? A coordenadora da oficina percebeu que alguns usuários se sentiam convocados a escrever e acabavam ficando angustiados com a publicação de seus textos. Perguntava-se, então, o que faria com tantos papéis que se acumulavam e qual era seu lugar diante deles.

Com essas perguntas, uma primeira torção aconteceu. Foi percebendo e acompanhando o que cada usuário já tinha como trabalho e forma de dar destino aos seus próprios textos ou o que faziam com seus escritos paralelamente à oficina. Pôde ver com cada um seu modo de lidar com a escrita e de encaminhar seus papéis. Fez uma pasta para cada participante e, a cada edição lançada, separava os textos a serem publicados arquivando na pasta de seu respectivo autor aqueles que ficavam com ela. Isso proporcionou que algumas pessoas a procurassem para acessar seu arquivo, para usar algum escrito dali em outra atividade ou com outro objetivo que não o jornal. 


\section{SAÚDE MENTAL}

Depois da criação das pastas, à medida que o tempo passava, a cada encontro surgia mais autonomia naquele grupo. Por exemplo, a coordenadora deparou-se com os usuários já reunidos na sala da atividade, com as mesas e cadeiras já organizadas por eles, antes que os chamasse para começar a oficina. Ela observou que um trabalho de arrumação, que antes fazia sozinha, passou a acontecer coletivamente. Além disso, eles mesmos começaram a distribuir as folhas e canetas para quem quisesse escrever, sem que fosse preciso convidá-los a isso, como fazia inicialmente. Em pouco tempo, a grande maioria das folhas já estava repleta de escritos. Um fato se sobressai a cada semana: eles escrevem muito! Percebeu-se que prescindiam cada vez mais de sua presença, funcionando como uma equipe de redação, conforme passaram a designar a atividade. Atenta a isto, a coordenadora se recolheu um pouco e continuou se deixando aprender com aquele grupo. Entendeu que seu lugar era o de sustentar, a partir do seu desejo, que aquele encontro semanal ocorresse na instituição.

Com o aumento dos participantes, outra questão se colocou, pois algo que já ocorria antes tornou-se evidente: ficou difícil para os usuários ouvirem uns aos outros. Renato e Sarah, por exemplo, começavam a falar ou a ler em voz alta de forma solitária no meio de uma conversa do grupo, sem que o coletivo estivesse preparado para ouvi-los. Não havia interlocutor ou diálogo. Um caos difícil de se organizar e ganhar liga.

A coordenadora assumiu uma postura mais ativa, diferente do trabalho de recolhimento que vinha fazendo. Uma vez, no meio de muito tumulto, durante uma oficina que não parecia render trabalho, Cássio, um usuário, começou ajudá-la a coordenar. Organizou quem ia falar, inscrevendo o nome daqueles que gostariam de ler e cedendo a palavra sucessivamente. Com essa participação, a coordenadora sugeriu que a cada encontro um usuário diferente coordenasse a oficina.

A partir de então, logo no início, uma pessoa se candidata a coordenador. Surpreendentemente, a partir dessa nova função operada por algum usuário, as falas, os escritos e as leituras passaram a ser mais endereçados. Renato, que falava quase sozinho interrompendo os outros, passou a pedir a palavra e trazer perguntas ao grupo, demandando sugestões sobre questões de sua vida. Depois, passou a ocupar o lugar de coordenação com grande frequência, ouvindo cada um e organizando as falas no grupo. Os textos começaram a conversar e surgiram alguns trabalhos coletivos: a partir do texto de Sarah, Elias pôde escrever sobre o mesmo tema que ela, como uma resposta ao que a primeira tinha escrito. Surgiram trabalhos coletivos: Fabiana ditava para 
Fausto escrever para ela Natan ensinou novos desenhos a Marília. Como disse Cássio, "a oficina pôde operar depois disso" e tem funcionado assim neste momento. Parece que, depois dessa função de coordenação, eles se autorizaram mais a intervir nas questões trazidas pelos outros participantes e a transferência se pulverizou entre eles que também estão, sobretudo, no lugar de destinatário uns dos outros, saindo da função exclusiva de pacientes em tratamento.

Heitor trabalhava como operador de tratores. Depois de um acidente de trabalho, não pôde mais exercer seu ofício, o que o deprimiu de forma muito grave e lhe tirou todo elã de vida. Ele "era as máquinas", só isso sabia fazer. Durante uma internação, iniciou a escrita de um caderno de forma intensa e solitária; depois de um longo tempo assim, começou a participar da oficina onde lia trechos desse livro, intitulado Vida sem vida. Era notório como ele se surpreendia muito com o retorno positivo dos ouvintes da leitura e, a partir do reconhecimento recebido, começou a escrever muitas poesias, falando dos tratores e de seu corpo como uma máquina.

No entanto, retrucaram no grupo que ele deveria esquecer os tratores, ao que ele disse: "esquecer não é apagar, não dá para apagar isso como se 86 apaga uma letra com uma borracha". Pouco a pouco escrever tornou possível "esquecer um pouco os tratores" e não apagá-los, ajudando-o numa mudança: "a cada vez que escrevo, eu mudo". Mudava de "tratorista para escritorista", o que é diferente de ser poeta, dizia ele. Escrever, portanto, deu um novo "sentido em sua vida", levando-o a retomar o convívio com a família, para a qual lê seus textos, e a criar laços com os usuários do serviço.

Com muitas poesias, criou, junto com sua técnica de referência, uma pasta que fica guardada no serviço. Nela, ele anexa e cataloga todos os seus poemas. Assim, a coordenadora notou que ele já separava, previamente ao dia da oficina, a poesia que gostaria de ler no grupo e que, outras vezes, escreve na hora do encontro. Sempre escreve com papel e caneta, depois digita no computador e imprime. Para as edições do jornal, envia-nos por e-mail as poesias que quer publicar e guarda todas em sua pasta.

A partir do ato de escrever, Heitor pôde recuperar alguma consistência do corpo que tinha se desvanecido, pôde ter seus textos reconhecidos por outras pessoas e organizar sua obra. Agora ele opera com a escrita, a partir de algo que não se apaga com a borracha, mas que é passado a limpo, rasurado. Um trabalho com a letra, como ele diz, que teve lugar na oficina de escrita. Foi de uma escrita solitária e melancólica a um livro compartilhado. Em uma bela poesia, nos conta do seu trajeto: 


\section{SAÚDE MENTAL}

\section{MUDANÇAS}

Vivo sempre desse jeito assim

Porque sou operador de máquinas

Que está saindo de mim

Mas não sai do pensamento

Dizem que estou mudando de tática

Termino escrevendo acontecimentos

Atuais e de outras datas

Acreditam que estou mudando

Escrevendo o que penso e relato

Escrevi tanto sobre o meu trabalho

E continuo escrevendo

Parece que não paro

Maitê era uma grande e bela atriz que escrevia de modo incessante livros e mais livros, sem publicá-los. Devido a um fracasso financeiro em sua carreira, às perdas acarretadas pela velhice, à destruição total dos laços que tinha na vida e a um completo abandono dos cuidados com o corpo, ela recorre a uma internação e inicia tratamento no serviço diariamente. O que predomina em seu caso é a vivência de angústia avassaladora e a certeza de que ela é muito melhor do que as outras pessoas que frequentam o CAPS, o que a impede de fazer vínculos com os outros usuários. Esteve por muitos meses apenas presente na oficina, sem produzir nada e sem conseguir ouvir as conversas no grupo, imersa em seus problemas. Precisávamos repetir seu nome algumas vezes, até que ela percebesse que falávamos com ela.

Em conversas após a oficina, falava à coordenadora da oficina do medo de sua obra acabar por se perder, quando ela não estivesse mais viva. A coordenadora respondia convidando-a a ler seus textos na oficina, mas nada a animava. Certo dia, inesperadamente, trouxe um de seus livros de contos e começou a ler um conto por encontro. Uma vez, pediu a outra pessoa que lesse para ela, pois estava rouca. Ouvir seu texto lido por alguém teve um efeito inédito para essa usuária. Segundo ela, isto lhe trouxe vontade de voltar a escrever, o que não fazia há anos. Com esse trabalho em curso, já leu um de seus livros para o grupo, começou a ler outro e passou a escrever pequenos escritos durante a oficina. Curiosamente, mostra interesse pelos comentários que fazem de seus textos e ainda faz questão de ouvi-los, mesmo que eles sejam bem delirantes. 
Recentemente, depois de um convite da coordenadora para criarem um blog para postar os textos que não saíam no jornal e suas produções antigas, ela aceitou e iniciou uma nova prática que também estava adormecida: a leitura de livros. Se antes Maitê ficava inerte no sofá do CAPS, hoje ela lê um livro atrás do outro. Ela, que vivia constantemente em plena angústia, com um corpo largado, pôde retomar a escrita e a leitura, recursos de que já dispunha, para regular o excesso. Reinvestiu a libido acumulada no eu, que a tomava sob a forma desse afeto avassalador, dando-lhe algum destino com o ato de ler/escrever. Pôde ainda ter sua obra testemunhada por outras pessoas, sem o risco de não ser jamais lida.

Fabiana escreve muito. Passa o dia a andar pelo corredor do CAPS sorrindo, às vezes gargalhando, e outras bem aflita. Fica muito contente e agradecida quando consegue folhas e caneta e encontra um canto mais quieto para sentar e escrever. Ela claramente organiza seu delírio escrevendo, faz contas e prescrições. Seus escritos são sempre cartas endereçadas a alguém (algum familiar, técnico do serviço ou algum usuário) e ela as entrega a seus destinatários ao longo do dia.

Técnicos e usuários não conseguem acompanhar muito a lógica de sua construção delirante, mas não deixam de escutá-la, retribuindo a doçura de sua presença e de suas perguntas. Parece que não importa para ela se seu interlocutor compreendeu o que disse ou interrogou, tampouco a resposta que ele dá à sua pergunta. Ela pede apenas, depois de uma fala muito confusa, que se "pisque o olhinho" para ela. Parece que Fabiana busca não uma leitura do que ela fala ou escreve, mas apenas que se acuse o recebimento do que disse, com uma piscadela.

Na oficina de jornal, ela continua seu trabalho incessante de escrita e cuidadosamente ouve atenta os textos dos outros, compartilhando suas interpretações muito delirantes do que ouviu, o que surpreende os outros leitores à sua volta. Sua leitura dos textos mostra de forma clara como o significante não tem nenhuma relação com o significado. No que se refere a seus textos, no entanto, ela nunca lê para o grupo as muitas páginas nas quais deposita sua escrita. Segundo ela, seus textos são "só para constar" e não para serem lidos. Inaugurou-se, assim, uma pasta com esse título para quem desejar fazer o mesmo. Ao final da oficina, ela sempre entrega à coordenadora um chumaço de folhas escritas e se desculpa pelo "trabalho" que lhe dará para organizá-las em sua pasta. Recentemente, passou a indicar as que devem ir para a sua pasta e as que se destinam ao lixo.

Parece que Fabiana usa da carta/letra em suas duas vertentes, tanto na sua dimensão de carta endereçada, quanto como um escrito cuja mensagem 


\section{SAÚDE MENTAL}

pouco importa, um escrito que não é para ser lido, compreendido, e sim para ser expedido, demonstrando a vertente da carta como pedaço de papel a ter um destino concernente à sua materialidade. Fabiana faz da carta/letra, lixo.

Três usuários, três percursos singulares com a escrita e com a leitura, que nos ensinam muito sobre o trabalho que sabem fazer com a letra e com o gozo de lalíngua e sobre os modos de enlaçamento com os outros que eles inventam a partir dos artifícios de escrita e leitura em uma oficina terapêutica.

\section{Considerações finais}

Ficou cada vez mais claro que, no que se refere à produção escrita do psicótico, não se trata de um texto a ser lido e interpretado, como se faz na neurose. Lacan (1972-73/2008) nos disse que um escrito não é para ser lido. É preciso (Lacan, 1955-56/2002), introduzir o sujeito no texto, assim como fez Freud com o livro de Schreber, tornando-se secretário do alienado. Isto quer dizer não avaliar a psicose em termos de déficit, mas pela própria lógica do inconsciente. Nesse sentido, tornar-se secretário do alienado não implica simplesmente tomar notas, mas sim introduzir o sujeito no texto e ordenar, no tempo, sua produção.

Assim, as intervenções da coordenadora da oficina situam-se a partir de um lugar de quem ouve as leituras atentamente, acusando recebimento junto com o grupo, sem interpretá-las. Além disso, tem a função de organizar as edições do jornal, separando os textos nas pastas por cada período de publicação, analisando com cada um o que fazer com eles, secretariando os papéis, cartas, fotos, desenhos que são produzidos na oficina, e às vezes fora dela, mas que são trazidos ali — um trabalho de secretariar a produção escrita daquelas pessoas e acompanhar o trabalho espontâneo feito por cada um com a escrita e a leitura.

A concepção que Lacan aprimorou ao longo de seu ensino sobre a letra/ carta como distinta do significante, portando uma materialidade como um pedaço de papel e seus traços, mais do que uma mensagem a ser transmitida, é de suma importância nessa oficina para examinarmos o lugar que nela assume o clínico e a função de circulação dos textos. Isso porque entendemos que a função eminente do secretário é a de expedir as cartas, o que remete a despachar as letras, livrando-se delas, e de que a circulação dos textos se aproxima da circulação dessa substância, da materialidade que se associa ao gozo. 
Esse ponto concorre para pensarmos o lugar do clínico como destinatário desses textos. Estarmos atentos ao fato de que o saber está do lado do psicótico e podermos ouvir não do lugar de quem sabe, possibilitou à coordenadora ocupar na oficina um lugar de endereçamento esvaziado de saber, ao qual os participantes podem direcionar seus escritos. Desfazem-se de seus papéis cobertos de escrita, deixam-nos sob seus cuidados, dando-lhe trabalho para organizá-los e compartilham seus escritos com os demais participantes na oficina. Assim, podem ceder um objeto, ter alguma perda de gozo e algum alívio, o que possibilita que a letra, como lixo, venha a se perder. A publicação, seja nas edições do jornal, seja na leitura ao grupo, remete-se à expressão "publixo" de Lacan (1972-73/2008), que aproxima o ato de publicação de um escrito com a ação de jogar objetos pela lixeira, fazendo da letra, lixo. Desse modo, veicula-se o gozo e produz-se alívio ao excesso que acomete o sujeito.

Concluímos que a oficina e a publicação dos textos parecem servir a esse grupo como reguladores da linguagem, o que faz com que consideremos os recursos de escrita e leitura utilizados neste trabalho como um modo de coletivização na psicose, fazendo com que seja possível para alguns, ou em alguns 90 momentos, passar da solidão do gozo a uma ligação com os outros, como nos diz Francisco com sua poesia:

Junto letras, enfileiro palavras,

Formo frase que façam sentido,

Caminho do conhecido ao desconhecido,

E nesse caminho a minha voz

Torna pessoas isoladas em nós (...)

Queremos entender esse sentimento

Que extravasa,

As vezes nos leva ao sublime,

Às vezes nos arrasa (...)

Sem fugir do passado,

Sabendo o quanto de mistério há nessa vida.

Viver é um negócio sério,

Se alguém duvida, olhe para dentro,

E descubra o quanto há lá

Que nem você sabe,

Seguir a correnteza de um rio

Sem saber aonde desague, 


\section{SAÚDE MENTAL}

Sem saber o que encontraremos

E pedir aos céus saber que vivemos.

\section{Referências}

Bastos, A. \& Freire, B. (2006). Sobre o conceito de alíngua: elementos para a psicanálise aplicada ao autismo e às psicoses. In A. Bastos (Org). Psicanalisar hoje. Rio de Janeiro, RJ: Contra Capa.

Brasil (2004). Saúde mental no SUS: os centros de atenção psicossocial. Ministério da Saúde, Secretaria de Atenção à Saúde, Departamento de Ações Programáticas Estratégicas. Brasília, 86 p.

Batista, M., \& Laia, S. (2012). A psicose ordinária. Belo Horizonte, MG: Scriptum Livros.

Freud, S. (2006a). Edição Standard Brasileira de Obras Psicológicas Completas de Sigmund Freud (ESB). Rio de Janeiro, RJ: Imago. 24 vols.

Freud, S. (2006b). As neuropsicoses de defesa. In Edição Standard Brasileira de Obras Psicológicas Completas de Sigmund Freud (ESB) (v. III, pp. 51-72). Rio de Janeiro, RJ: Imago. (Trabalho original publicado em 1894).

Freud, S. (2006c). Três ensaios sobre a teoria da sexualidade. In Edição Standard Brasileira de Obras Psicológicas Completas de Sigmund Freud (ESB) (v.VII, pp. 119-217). Rio de Janeiro, RJ: Imago. (Trabalho original publicado em 1905).

Freud, S. (2006d). Notas psicanalíticas sobre um relato autobiográfico de um caso de paranoia (dementia paranoides). In Edição Standard Brasileira de Obras Psicológicas Completas de Sigmund Freud (ESB) (v. XII, pp. 15-89). Rio de Janeiro, RJ: Imago. (Trabalho original publicado em 1911).

Greco, M. G. (2003). A letra em seu devido lugar. Recuperado em 15 dez 2017, de: $<$ http://poslit.letras.ufmg.br/pt-br/>.

Holck, A. L. L. (2010). Uma certa escrita. Arquivos da Biblioteca 7, p. 39-46.

Joyce, J. (2014). Retrato do artista quando jovem. Porto Alegre, RS: L\&PM.

Lacan, J. (1967). Pequeno discurso aos psiquiatras, 10 de novembro de 1967. Inédito. Recuperado de: $<$ http://www.ecole-lacanienne.net/pastoutlacan60.php $>$.

Lacan, J. (1998a). Seminário sobre a carta roubada. In Escritos (pp. 13-66). Rio de Janeiro, RJ: Jorge Zahar. (Trabalho original publicado em 1956).

Lacan, J. (1998b). Juventude de Gide ou a letra e o desejo. In Escritos (pp. 749-775). Rio de Janeiro, RJ: Jorge Zahar. (Trabalho original publicado em 1958).

Lacan, J. (2002). O seminário. Livro 3. As psicoses. Rio de Janeiro, RJ: Jorge Zahar. (Trabalho original publicado em 1955-56). 
Lacan, J. (2003). O Aturdito. In Outros escritos (pp. 448-497). Rio de Janeiro, RJ: Jorge Zahar. (Trabalho original publicado em 1966).

Lacan, J. (2005). O seminário. Livro 10. Angústia. Rio de Janeiro, RJ: Jorge Zahar. (Trabalho original publicado em 1962-63).

Lacan, J. (2007). O seminário. Livro 23. O Sinthoma. Rio de Janeiro, RJ: Jorge Zahar. (Trabalho original publicado em 1975-76).

Lacan, J. (2008). O seminário. Livro 20. Mais, ainda. Rio de Janeiro, RJ: Jorge Zahar. (Trabalho original publicado em 1972-73).

Laia, S. (2001). Os escritos fora de si-Joyce, Lacan e a loucura. Belo Horizonte, MG: Autêntica/Fumec.

Laurent, E. (1995). Versões da clínica psicanalítica. Rio de Janeiro, RJ: Jorge Zahar.

Maleval, J. C. (2002). La forclusión del Nombre del Padre: el concepto y su clínica. Buenos Aires, Argentina: Paidós. 448p.

Mandil, R. (2003). Efeitos da letra: Lacan leitor de Joyce. Rio de Janeiro, RJ/Belo Horizonte, MG: Contra Capa Livraria/Faculdade de Letras UFMG.

Mandil, R. (2010). Escritor, mas não poeta. Arquivos da Biblioteca 7, 53-63.

Miller, J-A. (2003). A invenção psicótica. Opção Lacaniana, 36, maio.

Muñoz, N. et al. (2014, dez.). Incorporando histórias: a recomposição do corpo próprio na perspectiva dos usuários de serviços de saúde mental. Rev. Latinoam. Psicopat. Fund., São Paulo, 17(4), 872-886.

Zenoni, A. Abrecampos - Psicanálise e instituição. Revista de Saúde Mental do Instituto Raul Soares, I(0), 2000.

\section{Resumos}

(The act of writing in psychoses: its functions and fates in a literary workshop)

This paper discusses the experience on monitoring psychotic patients during a literary workshop aimed at writing and producing a journal in a CAPS III. It was our goal to survey the effects of the act of writing, especially when writing along with others. The procedure is based on the memories of Dr. Schreber, on James Joyce's literary work, and on fragments of our work in the workshop, based on S. Freud and J. Lacan. We conclude that the effects of participating in collective activities comprise addressing others and the production of writing intended for the trash bin, resulting in an excess of jouissance.

Key words: Psychoses, wrinting, psychoanalysis, literary workshop 


\section{SAÚDE MENTAL}

(L'écriture at les psychoses: ses fonctions et ses destins dans un atelier litteraire)

Cet article décrit l'expérience d'un accompagnement de sujets psychotiques lors d'un atelier littéraire qui visait à rédiger et à produire un journal dans un centre CAPS III. Le but de cette recherche était d'inventorier les effets de l'acte d'écrire, principalement d'écrire avec les autres. Le procédé s'appuyait sur les mémoires de Schreber, sur l'œuvre littéraire de James Joyce et sur l'utilisation de fragments de travail de l'atelier, ayant comme base S. Freud et J. Lacan. On conclut que les effets de participation dans les activités collectives comprennent le fait de s'adresser à l'autre et de produire des textes destinés à la poubelle, ce qui permet d'extraire un excès de jouissance.

Mots clés: Psychoses; écriture; psychanalyse; atelier litteraire

(La escritura en las psicosis: sus funciones y destinos en un taller literário)

El artículo aborda la experiencia de acompañar a pacientes psicóticos en un taller literario de escritura y producción de un periódico en un CAPS III. El objetivo consiste en cotejar los efectos del acto de escribir, sobre todo, del escribir unos junto a otros. El procedimiento se basa en las memorias de Schreber, en la obra literaria de James Joyce y en fragmentos del trabajo durante el taller, basados en lo planteado por S. Freud y J. Lacan. Se concluye que los efectos de la participación en las actividades grupales comprenden la orientación hacia el otro y la producción de la letra que se convierte en basura, gracias a la cual se extrae el exceso de goce.

Palabras clave: Psicosis, escritura, psychoanalysis, taller literário

(Der Prozess des Schreibens und Psychosen: seine Funktionen und Ziele in einem literarischen Workshop)

Der vorliegende Artikel kommentiert die Erfahrungen, die während einer Begleitarbeit von psychotischen Patienten gesammelt wurden. Diese nahmen an einem literarischen Workshop in einem CAPS III teil, dass zum Ziel hatte ein Tagebuch zu schreiben und zu produzieren. Die Auswirkungen des Schreibaktes wurden erfasst, insbesondere wenn man zusammen mit den anderen schrieb. Die angewandte Methodik stützt sich unter anderem auf die Erinnerungen von Schreber, auf das literarische Werk von James Joyce und auf Fragmenten der Begleitarbeit während des Workshops, basierend auf S. Freud und J. Lacan. Man kommt zum Schluss, dass die Auswirkungen der Teilnahme an den gemeinschaftlichen Aktivitäten die Ansprache des Anderen beinhalten, sowie die Produktion von Texten, die im Müll landen, was zu einem Überschuss an Genuss führt.

Schlüsselwörter: Psychosen, Schreiben, Psychoanalyse, Literarischer Workshop 
Citação/Citation: Freitas, M. N. de, \& Bastos, A. (2019, março). A escrita nas psicoses: suas funções e seus destinos em uma oficina literária. Revista Latinoamericana de Psicopatologia Fundamental, 22(1), 72-94. http://dx.doi.org/10.1590/1415-4714.2018v22n1p72.5.

Editores do artigo/Editors: Profa. Dra. Ilka Franco Ferrari.

Submetido/Submitted: 2.9.2018/ 9.2.2018 Revisado/Revised: 27.10.2018 / 10.27.2018

Aceito/Accepted: $18.12 .2018 / 12.18 .2018$

Copyright: (C) 2009 Associação Universitária de Pesquisa em Psicopatologia Fundamental/ University Association for Research in Fundamental Psychopathology. Este é um artigo de livre acesso, que permite uso irrestrito, distribuição e reprodução em qualquer meio, desde que o autor e a fonte sejam citados / This is an open-access article, which permits unrestricted use, distribution, and reproduction in any medium, provided the original authors and sources are credited.

Financiamento/Funding: Este trabalho não recebeu financiamento / This work received no funding.

Conflito de interesses/Conflict of interest: Os autores declaram que não há conflito de interesses / The authors have no conflict of interest to declare.

\section{Manoela Nunes de Freitas}

Doutoranda em Teoria Psicanalítica pela Universidade Federal do Rio de Janeiro - UFRJ (Rio de Janeiro, RJ, Br); Especialista em Clínica Psicanalítica em Instituição pelo Instituto de Psiquiatria da Universidade Federal do Rio de Janeiro - IPUB/UFRJ; Psicóloga do CAPS III Franco Basaglia (Rio de Janeiro, RJ, Br).

Av. Pasteur, 250, fundos. Pavilhão Nilton Costa

22290-140 Rio de Janeiro, RJ, Br.

https://orcid.org/0000-0001-8219-3536

manoelanfreitas@gmail.com

\section{Angélica Bastos}

Professora do Programa de Pós-graduação em Teoria Psicanalítica do Instituto de Psicologia da Universidade Federal do Rio de Janeiro - UFRJ (Rio de Janeiro, RJ, Br); Psicanalista; Membro da Escola Brasileira de Psicanálise e da Associação Mundial de Psicanálise; Bolsista de Produtividade em Pesquisa do CNPq.

Av. Pasteur, 250, fundos. Pavilhão Nilton Costa

22290-140 Rio de Janeiro, RJ, Br.

https://orcid.org/0000-0003-4764-2660

abastosg@terra.com.br

This is an open-access article, which permits unrestricted use, distribution, and reproduction in any medium for non-commercial purposes provided the original authors and sources are credited. 